DOI: 10.20472/IAC.2019.048.044

\author{
SEIYEONG PARK \\ Seoul National University, South Korea \\ JUNHYE KWON \\ Seoul National University, South Korea
}

\title{
THE STUDY FOR IDENTIFYING THE RELATIONSHIP BETWEEN SHIFT-TYPE AND VOLUNTARY EXERCISE TRAINING AMONG KOREAN FIREFIGHTERS
}

\begin{abstract}
:
It is important for firefighters to maintain high levels of fitness since they are responsible for protecting the safety and well-being of the public. In Korea, about $70 \%$ of firefighters ask to accept the 3-circuit system which is considered to be effective in recovering from fatigue, reducing commuting time, and maintaining a regular daily routine. However, the effect of the 3-circuit system on their fitness management has not been demonstrated. In this context, the present study aims to examine the impact of shift-type on exercise training (ET) and to identify the interaction effect between shift-type and city size on ET among Korean firefighters. The data used in the present study were collected in 2017 targeting incumbent outside workers among Korean firefighters $(N=5,196)$. A series of logistic regression models were analyzed to investigate the association between ET and individual, health-behavioral, work-related variables and the interaction term between shift-type and city size. The main results of the present study were as follows. First, Korean firefighters were seemed to be more involved in ET when the age was lower. This is because firefighters with lower age levels are in relatively low-ranking positions, which they are responsible for activities requiring high levels of fitness in the field. Second, the interaction effect between shift-type and city size on ET was significant in the full model. That is to say, firefighters working in the 3-circuit system less participated in ET than firefighters working in the 21-circuit system and the gap was bigger in large cities than in small towns. If there are more consecutive breaks for firefighters, they will spend time with their family or friends or take rests rather than participating in ET. Especially, there are more options to enjoy leisure in large cities, and also it could be relatively easy to participate in ET at work for firefighters working in small towns because the number of cases in operation in small towns are not as high as that of large cities. The present study suggested that it is early to accept the 3-circuit system in current Korean state. It is more important to set up the environment that can be applied with a three-cycle work system in order to achieve the expected effectiveness of firefighters.
\end{abstract}

\section{Keywords:}

Korean firefighter, outside worker, shift-type, exercise training 